\title{
CONQUISTE SUA VAGA NO MERCADO DE TRABALHO
}

Thiago José de Azevedo Loureiro ${ }^{1}$ Camila Sayonara Barbosa de Oliveira ${ }^{2}$

\section{RESUMO}

O Projeto de Extensão "Conquiste sua vaga no mercado de trabalho" realiza-se por meio de palestras em escolas públicas de ensino médio da Região Agreste do Rio Grande do Norte. O objetivo do projeto é levar conhecimentos aos jovens que estão em busca de ingressar no mercado de trabalho pela primeira vez. Durante as palestras os quarenta alunos voluntários abordam duas temáticas: preparação para entrevistas de emprego e elaboração de currículos. A meta inicial do projeto era beneficiar 200 jovens, mas em apenas seis meses de execução já foram contemplados, aproximadamente 1.300. Entende-se que o projeto é importante também para promover o Instituto Federal de Educação, Ciência e Tecnologia do Rio Grande do Norte (IFRN) junto à sociedade.

Palavras-chave: seleção de pessoas, entrevista de emprego, elaboração de currículo.

\section{INTRODUÇÃO}

Pode-se dizer que ter profissionais de qualidade é um fator competitivo no mercado dinâmico e globalizado que as empresas enfrentam no seu dia a dia. Segundo Chiavenato (2008) "sem as pessoas não há dinâmica organizacional".

Para o SEBRAE (20--) "o objetivo do processo de seleção de pessoal é escolher o candidato com melhores conhecimentos e habilidades para desempenhar a tarefa que Ihe for atribuída."

Atualmente, na maioria das vezes, as organizações utilizam durante a seleção de pessoas, dentre outras, duas técnicas: análise de currículos e entrevistas. A análise de currículos permite ao selecionador, obter uma visão resumida das experiências profissionais e formação acadêmica de cada candidato. A entrevista permite ao selecionador: verificar as atitudes, constatar a veracida- de das informações descritas no currículo, obter mais informações sobre experiências profissionais e/ou formações acadêmicas, entre outros.

Diante da importância que a entrevista tem no processo de seleção de pessoas e, consequentemente, inserção dos candidatos no mercado de trabalho, percebeu-se a relevância de realizar um Projeto de Extensão no Campus Nova Cruz do Instituto Federal de Educação, Ciência e Tecnologia do Rio Grande do Norte, denominado "Conquiste sua vaga no mercado de trabalho", para melhorar o desempenho dos jovens que estão em busca de oportunidades no mercado de trabalho, especialmente aqueles que estão concluindo o ensino médio em escolas públicas da Região Agreste.

A metodologia da atividade de extensão dar-se por palestras, proferidas pelos alunos voluntários, nas quais são passadas informações sobre elaboração e organização do currículo e

1 Professor de Administração do IFRN Campus Nova Cruz.

2 Aluna do Curso subsequente em Administração. Bolsista do projeto. 
como deve ser o comportamento do candidato numa entrevista de emprego.

\section{DESENVOLVIMENTO}

O Projeto de Extensão "Conquiste sua vaga no mercado de trabalho" iniciou-se em novembro 2013, inicialmente os quarenta participantes (todos voluntários) realizaram estudos e pesquisas para aprofundar seus conhecimentos nas temáticas centrais do projeto e melhorar uma apresentação em slides que o coordenador já utilizava em suas aulas para alunos dos cursos Técnicos de nível médio em Administração e Química.

Após essa fase inicial, as primeiras palestras (figuras 1 e 2) começaram a ser realizadas. As duas primeiras ocorreram no próprio Campus, em fevereiro de 2014, para, aproximadamente, 50 (cinquenta) alunos do primeiro período do Curso Técnico Subsequente em Administração e do Programa Nacional de Acesso ao Ensino Técnico e Emprego (PRONATEC).

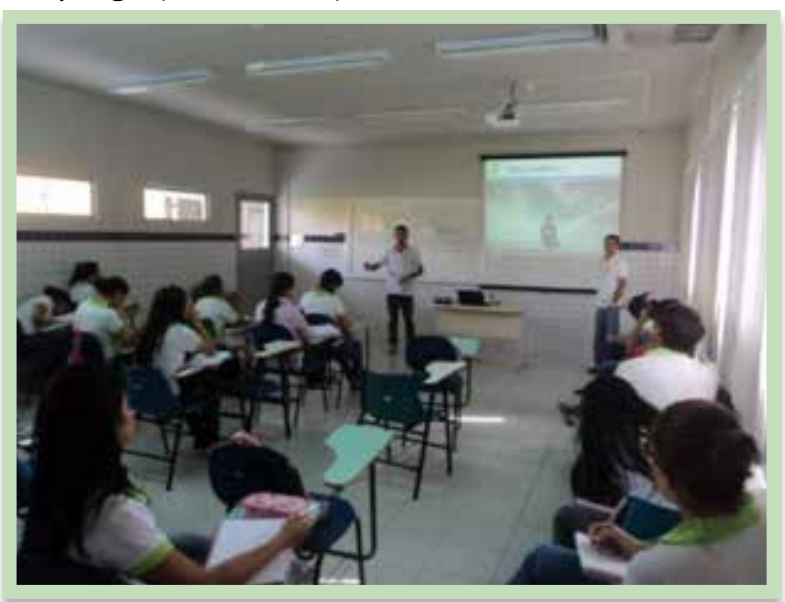

Figura1: IFRN, Campus Nova Cruz

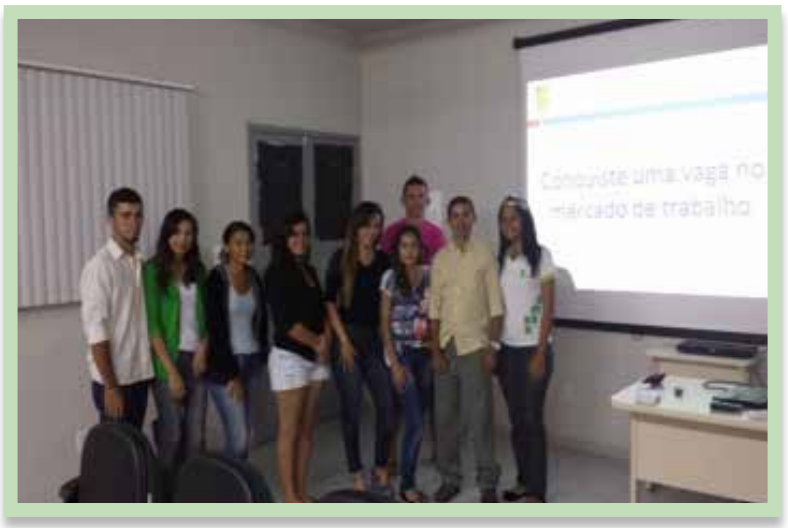

Figura 2: palestra para alunos do PRONATEC

Ainda em fevereiro, o projeto começou a percorrer as escolas públicas das cidades da Região Agreste. A primeira instituição foi a Escola
Estadual Djalma Marinho (figura 3), na qual 75 alunos, concluintes do ensino médio, participaram do projeto. Em seguida vieram as Escolas Estaduais Alberto Maranhão e Rosa Pignataro, nessas participaram cerca de 220 jovens.

Em Março, o projeto retornou à Escola Estadual Rosa Pignataro e foi à Câmara Municipal de Nova Cruz. Participaram das palestras aproximadamente 85 jovens. Nesse mês, pela primeira vez foi realizado fora de Nova Cruz/ $\mathrm{RN}$, mais especificamente nos municípios de Monte das Gameleiras e Serra de São bento, respectivamente nas escolas estaduais Felismino José da Costa e Joaquim Torres (figura 4).

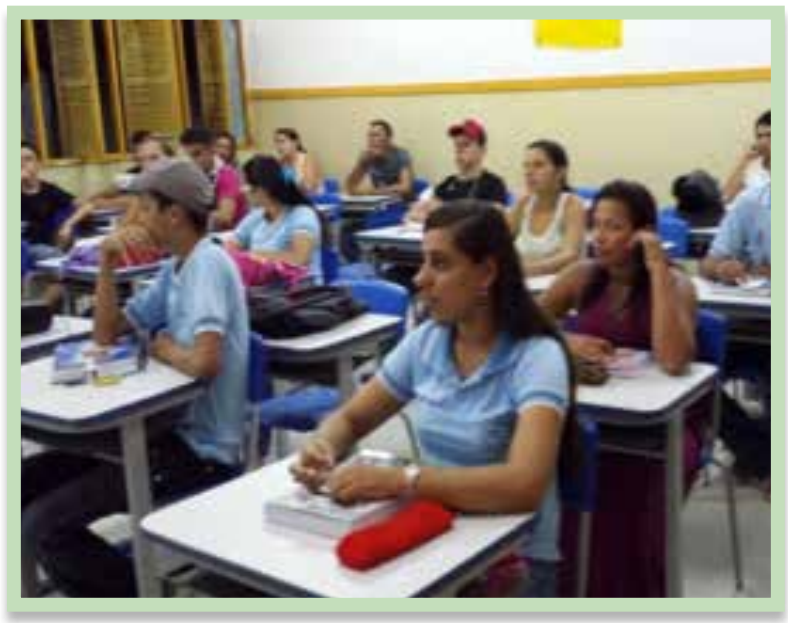

Figura3: palestra na escola Estadual Djalma Marinho

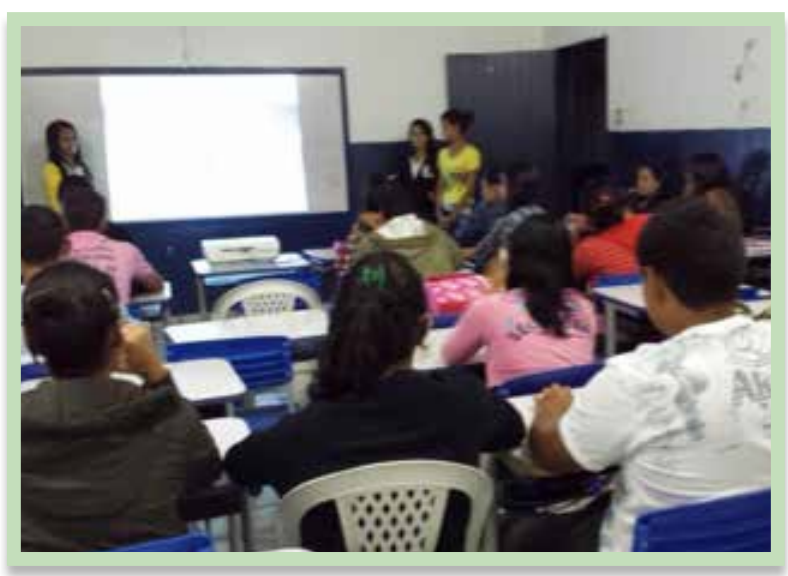

Figura 4: palestra na escola estadual Felismino José da Costa

No mês de abril, $O$ "conquiste sua vaga no mercado de trabalho" esteve em Lagoa D'anta/RN levando conhecimentos para 20 jovens do serviço de convivência e fortalecimento de vínculos. Em maio, 180 alunos da Escola Estadual Filomena Azevedo na cidade de Santo Antônio/RN e 200 do IFRN/Campus Caicó participaram do projeto. (figuras 5 e 6 ). 


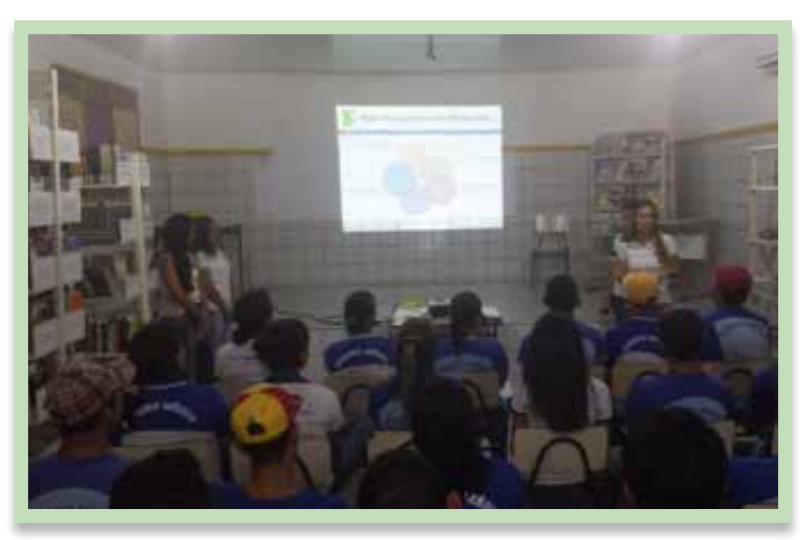

Figura 5: Escola Estadual Filomena Azevedo

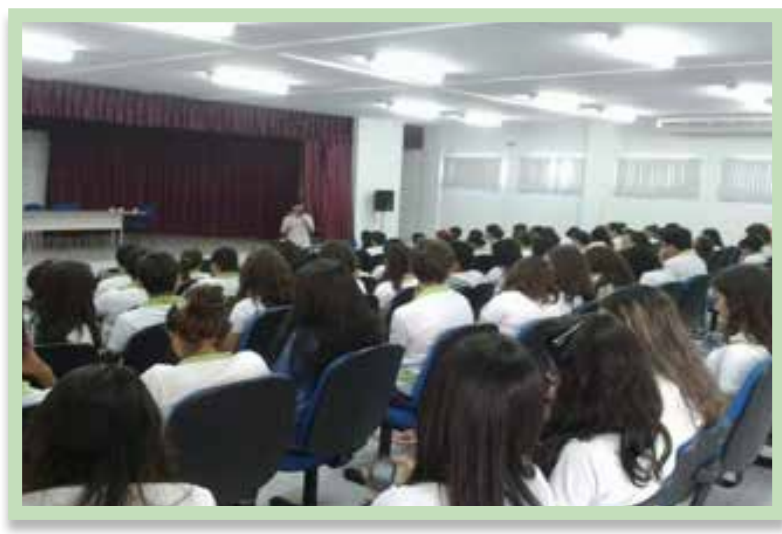

Figura 6: IFRN, campus Caicó/RN

Em Junho, foram feitas três palestras. A primeira na Universidade Estadual do Rio Grande do Norte para 20 alunos do curso superior em Ciências da Computação, a segunda no Campus Canguaretama do IFRN para alunos do PRONATEC e a última para alunos concluintes das turmas do PRONATEC, Campus Nova Cruz do IFRN e do sistema " $\mathrm{S}$ ". Ao todo participaram das palestras, aproximadamente 250 jovens.

Por fim, em julho, o "conquiste sua vaga no mercado de trabalho" esteve presente na Câmara Municipal de Santo Antônio e no primeiro período do curso técnico em Administração, modalidade subsequente, do IFRN, Campus Nova Cruz/RN, contemplando 110 jovens.

Para verificar os resultados das palestras, ao final de cada uma delas, os participantes indicam, por meio de questionários, as três informações que não sabiam e consideram mais importantes. possuem currículos. Por isso, esse projeto é de suma importância para facilitar a inserção de jovens no mercado de trabalho.

Para os voluntários, o projeto torna-se relevante por desenvolver a oralidade, diminuir o receio de falar em público e capacitá-los para trabalhar em equipe e manter boas relações interpessoais.

No que se refere ao número de participantes, é correto afirmar que o projeto superou e muito sua meta inicial de 200 jovens, uma vez que já atendeu mais de 1.200, em 22 palestras realizadas.

Quanto ao conteúdo apreendido pelos alunos contemplados com as palestras, os 10 (dez) mais citados foram: (1) ligar rapidamente ou enviar e-mail agradecendo a oportunidade de participar do processo de seleção, (2) manter postura profissional antes, durante e depois das entrevistas, (3) vestir-se conforme empresa/ função, (4) pesquisar sobre a empresa, (5) levar currículo, (6) pesquisar sobre a função que está concorrendo, (7) usar as mídias sociais de forma adequada, (8) ter currículo atualizado e acessível onde quer que esteja, (9) ser sempre verdadeiro nas respostas e (10) ter cuidado com a aparência física.

Por último, é importante destacar que, além de todos os resultados diretos, o projeto contribui para promoção do IFRN, Campus Nova Cruz em toda Região Agreste, facilitando assim, o desenvolvimento de outras ações junto à sociedade.

\section{REFERÊNCIAS}

CHIAVENATO, Idalberto. Gestão de pessoas 3. ed. Rio de Janeiro: Elsevier, 2010.

SEBRAE. Seleção e recrutamento de pessoal. Campo Grande, MS: [s.n, 20--]. Disponível em: <http://www2.ms.sebrae.com.br/uploads/UAl/ fichastecnicas/recrutamento.pdf >. Acesso em: 15 jul. 2014.

\section{CONCLUSÃO}

A entrevista é uma das técnicas de seleção de pessoas comumente utilizada pelas empresas. Percebeu-se durante as palestras que os jovens da Região Agreste não estão preparados para participar de entrevistas de empregos e não 